\title{
Multinationals, Local Practice, and the Problem of Ethical Consistency *
}

\author{
Arnold Berleant
}

\begin{abstract}
.
The business practices of multinational corporations raise many provocative moral issues and offer a touchstone for some fundamental ethical concepts. This essay identifies a wide range of problems but centers on the matter of consistency in corporate policy between foreign and domestic practices and the kind of generality of standards that is required to achieve consistency. Two considerations are singled out for illustrative discussion: wage scales and bribes. Proposals are offered for achieving consistency and generality in each case, the principle of contextual generality for the first and the notion of structural universals for the second.
\end{abstract}

\section{The problem}

The widespread practice of payments made by corporation officers to foreign individuals instrumental in securing government contracts provides the ground on which many moral issues in business converge. At the same time it raises questions so basic to the entire matter of business morality that from a clear resolution of these issues one could develop a systematic view of business ethics and, indeed, of moral philosophy in general. This is hardly anything to wonder at, however, small the problems of ethics are largely occasioned by difficulties in social relations and thus have always traced their roots to the field of practice.

What are some of the ethical questions that multinational corporations encounter and what are the general issues they raise for moral philosophy? Once we define the scope of our problem, we can stake out what ground to cultivate more intensively.

(1) What is an appropriate commission for arranging a sale? With a sales division as a necessary complement to production in a market economy, the matter of its proper share of cost and income is of central concern. Since a reasonable balance must be established among the competing claims of various basic functions

*An earlier version of this paper was presented at the Fifteenth Conference on Value Inquiry at the SUNY College at Genesco on 17 April 1981 and published in Proceedings of that conference. 
of a business to a proper share of the total price, functions of production, management, and distribution, attention must be given to customary commission rates and the effectiveness of a sales operation should be encouraged and rewarded. If, however, an inordinate cost is sustained in securing contracts, what are the effects of this practice on the total enterprise? Bribes, in particular, as well as excessive commissions, raise questions about the integrity and purpose of the enterprise as a whole and of its actual role in national economies. Where, for example, do the bribes go? Embedded in these concerns is the basic ethical issue of fairness.

(2) What is the difference between a commission, a facilitating payment, a gift, and a bribe? This is more than a quest for definitions, nor can an answer be regarded as purely arbitrary. There are conventional usages that can clarify these terms and common practices that exemplify them. Is the difference between a gift and a bribe simply a matter of the amount of money involved? Does the acceptable size of a gift bear some relation to the amount of the sale or must it always be small? At what point does excess occur and is guilt incurred? Is a facilitating payment merely a euphemism for a bribe? Is a minor payment no different in intent and effect yet different in moral status? Herein lies the general question of the relation between degree and offense.

(3) Are standards of moral behavior simply

Journal of Business Ethics 1 (1982) 185-193. 0167-4544/82/0013-0185\$00.90 Copyright @ 1982 by D. Reidel Publishing Co., Dordrecht, Holland and Boston, U.S.A. 


\section{Arnold Berleant}

established custom or should they serve as models and guides for common practice? In raising the fundamental problem of the relation between custom and morality, we face the force of moral obligation. To what extent should our explicit precepts echo the conventional practices of a society? If they are no more than reflections, there would then appear to be no guiding role for morality and it merely becomes an intellectual panoply to decorate and protect the status quo. On the other hand, morality has its source, both etymologically and historically, in social custom, and such custom is shaped and modified continually to assist societies in carrying on social life and in ensuring survival, safety, and well being. Must morality find its authority in some independent source or does it emerge from social practices as the most effective means of achieving social good? Does the impetus for an examination of ethical practices in business lie in justifying what is done or does it lie in changing and guiding future practice? If the latter, on what basis and with what moral force can such guidance be extended?

(4) Yet another question concerns the relation between ethics and practice. What place should moral principles take in the conduct of business? Are they ever proper guides in making business decisions? Assuming they are,' should moral convictions take precedence in business practice? If the primary obligation of a manager is to ensure the survival and profitability of his enterprise, to what extent do moral claims qualify or even oppose those ends? To cite one example, should a product harmful to the workers manufacturing it or to the consumer using it be discontinued even though these others are willing to persist? Such questions raise the contextual issue of the place of a business enterprise in the social economy and the correlative matter of the party most responsible for this moral concern. Should industry be expected to be self-policing or should it require legislation to ensure that everyone conform to the same standard?

(5) Finally, there is the matter of contrary customs in different places. How should a company be guided when local practices differ? The practice of giving bribes to local officials in order to secure a contract is a particularly dramatic instance of this. If the practice is so widespread in one country as to be a general expectation not warranting special comment, and yet scandalous or illegal in another, what policy should a corporation follow? Should it reject the custom and risk the loss of contracts or should it observe the practice and chance public disapproval at home? Does the nature of the product involved or the location or character of the country have any bearing on the rightness of the decision? No more difficult moral issue exists than that which raises the matter of ethical relativism, for moral principles, like knowledge, appear to demand universality. A principle that holds here but not there, then but not now, 
appears to be no more compelling than a physical law once considered true and now disproved. Its claim to authority seems to have disappeared.

International business, then, by its visibility and the scope of its operations, becomes the focal point for a set of critical moral issues that have no facile solution and yet cannot be set aside. Morality is concerned foremost with practice, and the usual exhortations to individuals facing such problems to act according to conscience or to pursue their private good simply do not apply in a direct way. Only individuals and not institutions can be said literally to possess a conscience. Moreover, business policy and actions are not exclusively personal matters; there are deep social interests that lie at their core. For a social institution embodying the interests of various groups within the society, a solution appropriate to an individual is of little help. Indeed, by such cases as this, private answers betray their inadequacy. We must seek a social solution to a social problem.

The conduct of corporate business, and of multinational corporations in particular, generates a large set of interlocking problems, then, most of which cannot be treated here. Central to them all, however, is the issue raised by the necessity of facing and reconciling different and opposed moral practices.

Puzzling out an answer to the question of ethical relativism in international business may, however, suggest a direction for dealing with issues raised by some of the other questions. 


\section{The moral claim}

From the earliest period of philosophical reflection, the variety of local practices has posed a major challenge to attempts to achieve ethical judgments that are uniform and that exercise the same moral force in all places and at all times. Such differences troubled Socrates and Plato deeply, and the attempt to reconcile moral diversity by establishing a common principle has been a central motive of ethical philosophy in succeeding centuries. Yet one must sadly acknowledge that there has been little progress since classical Greece in settling the issue.

Of the endless examples, one from the world of international business will suffice for the moment. The egregious instances of large sums paid by American corporations like Lockheed Aircraft to secure Japanese contracts excited strong protests once they were made public. Here the issue appears clearly: a practice customary in one country is not in another. Legality, however, raises yet a separate issue. While such payments seemed to be customary in Japan ${ }^{1}$, there was a question of their legality. Three principal politicians who received Lockheed payments were later indicted for solicited bribery but were not convicted, and two of them were subsequently re-elected. A contrary situation was true in this country. While such payments were not illegal here, they were not considered customary.

It is worth observing, though, that the secrecy with which everyone involved participated in the transaction seems to be an acknowledgement of public disapproval. There is something intuitively repugnant to our moral sense in the practice of secret payments. Yet at the same time we must recognize the multitude of common practices in every society that are technically illegal but nonetheless accepted quietly by the public as well as by those whose responsibility it is to uphold the law. Automobile driving practices are notoriously variable from place to place, different kinds and degrees of technical illegality being not only accepted but expected, from exceeding the speed limit to preempting a left hand turn and double parking. There are numerous other instances of accepted illegalities, such as hiring people off the books and making house alterations without securing building permits. The difference between de jure and de facto practices is well known and essential in recognizing un publicized or clandestine acts as common and even standard behavior. There is always a private face behind every public one.

Privacy or even secrecy, then, is no necessary condemnation of an act, although it may reflect its equivocal character. Nor are the more open instances of practices whose moral status varies from

\footnotetext{
${ }^{1}$ Neil H. Jacoby, Peter Nehemkis, and Richard Eels, Bribery and Extortion in World Business (Macmillan, New York, 1977) p.164.
} 
community to community evidence of confusion or shortcoming. The root question here concerns the claim of generality: To what extent ought a practice be observed by everyone? How commonly should it be accepted and followed? Though variable, custom has its basis in social traditions; so, too, does the expectation of uniformity in practice.

The logic of consistency requires that a principle apply universally in all similar cases at the risk of inconsistency and consequent falsity. A single exception proves the rule false. The logic of practice, on the contrary, is more malleable and forgiving. It recognizes that situations, even in their essential character, are never identical, and that wisdom and justice require discretionary judgment. The mechanical simplicity in applying a rule with indiscriminate universality fails to recognize the human cost that must be paid in a degree that varies from inappropriateness to direct harm. Nowhere is this conflict illustrated with more unflinching yet poignant effect than in the moral philosophy of Kant, who was forced to exclude consequences entirely from moral judgment in order to secure the universality of rule. Even the application of positive law recognizes the necessity of discretionary judgment by the court, although it accepts absolute uniformity as a desideratum. Thus the universality of a logical principle must face the universality of moral variability. The modification of a principle by individual circumstances is everywhere practiced.

To claim this is not to offer an argument for expedience or arbitrariness. Consistency imposes a genuine and necessary requirement. Does this mean that these competing claims are irreconcilable? I should like to suggest that they are not: the problem lies in establishing a balance between 
Arnold Berleant

universality and localism. Like Aristotle's moral virtue, there is a variable mean or balance point here, one whose location depends on the particular circumstances. If we are directed by the universality of practice and not the universality of logic, we can recognize that such an intermediate point is characteristically sought in cases of moral conflict between groups. And it is typically when such conflict develops that the question arises.

How, then, are we to determine the degree and kind of generality of practice that is appropriate in any particular case? By what standards, to apply the question to business, should a multinational corporation be guided? By the customs and laws of the country from which it originates and where central control is exercised or by the differing standards of the countries in which it carries on its affairs?

This question might not seem to arise in cases of a strictly national enterprise; such a business concern is presumably bound by the customs and laws of the country within which it operates. Here, however, differing regional practices may raise the same ethical questions as in international business. The treatment of employees, for example, may vary from one part of the country to another. By what policy should a company be guided, a uniform one or a policy that reflects the conditions and customs of the local community? This problem often arises when questions are raised concerning the employment and promotion of women or members of minority groups or regarding different wage scales. Legislation requiring uniformity may be a policy imposed by the state; it does not necessarily resolve the ethical issue.

Before we can develop a standard to determine the extent of generality, that is, how broadly a policy is to apply, we must first face a crucial problem. If we accept the limited scope of a moral rule, would not this allow the possibility that any practice could be pursued morally unscathed? Local practices can condone a diabolical variety of injustices that, by a strictly relativistic local standard, would not be injustices at all. Demeaning conditions of work, exploitative wage scales, wanton waste of resources, extensive environmental pollution and irredeemable destruction of the land, the calamitous disruption of a social system - it is easy to expand this list and specify the instances. Wouldn't a standard that does not reflect the claim of moral universality be an invitation to the rape of a land and its people?

Discretionary moral judgment does indeed present difficulties. Yet these are not restricted to such 
circumstances alone. If casuistry, which presumes to supply rules of conduct for particular cases, requires some discretion in identifying when instances of these cases are present so that one will know which rule to apply, so an absolute ethics, in offering moral principles of universal scope, demands discriminating judgment all the more. In so far as human affairs possess no mechanical uniformity, blind formulas cannot replace considered judgment.

Moral limits do exist, however, not by the decree of a supernatural being or the edict of a dogma. They reside in the very conditions in which a society must carry on its activities so as to ensure the survival and well being of its members. These conditions are not stipulated by any political body or social movement; they are the fundamental physical and social requirements for the continuance and welfare of any social group. A study of the sciences that deal with the human organism and its forms of organization and development shows that there are common basic traits and goals that are manifested, albeit in different social and institutional forms, by every human group. ${ }^{2}$ Protection, nourishment, reciprocity and the means of social cohesion and continuity, creative growth in thought and action, these are some of what I have termed structural universals. It is from them that specific patterns of behavior and belief develop in response to particular conditions of place and history. ${ }^{3}$ Such are the conditions under which every society must live and they become their moral limits. These results of the biological and behavioral sciences are not new; they have long been anticipated in philosophical thought, as in this observation Spinoza made in the seventeenth century:

“(T)he foundation of virtue is the endeavor to preserve one's own being, and... happiness consists in man's

\footnotetext{
${ }^{2}$ Arnold Berleant, "Ethics and Science: Some Normative Facts and a Conclusion,” Journal of Value Inquiry XI (1977), 244-258.

${ }^{3}$ Ibid., p. 256.
} 


\section{Multinationals and the Problem of Ethical Consistency}

power of preserving his own being... . (M)en... who seek what is useful to them in accordance with reason... desire for themselves nothing, which they do not also desire for the rest of mankind, and, consequently, are just, faithful, and honourable in their conduct."

It is within such limits and by such structural universals, then, that particular actions can be judged. These do not lead to the universality of specific practices, however, for differing forms of marriage, methods of group organization and decision making, patterns of diet, the entire complex of beliefs and actions that compose a culture represent differing responses to physical, social, and historical conditions. Sharing basic universals, then, does not mean following identical rules and practices; indeed, it usually requires different practices to attain the same fundamental ends of survival and well being. Here moral equality does not entail moral uniformity.

We have here a basis for considering the ethical status of institutions and practices in business as well as elsewhere in society. A local practice that enables the community to continue and flourish, both for its individual members and collectively, is justifiable on those grounds. To the degree that it impedes these ends, it is condemnable. This is no moral stipulation; it reflects universal practice and is the bedrock on which particular moral codes are elaborated and to which they respond. The foundation of morals upon mores is verified by history, by practice, and by the arguments of ethical philosophers, sometimes candidly, sometimes implicitly. ${ }^{5}$

When groups enter into economic and other relationships, they share common interests and common ends, and from this we can derive a principle of generality; this is that the generality of a practice must be determined by the range of its significant effects on those involved and affected by it. When the practice transcends local boundaries to implicate others, the range of significant involvement by participation in that activity or through its effects determines the moral community and hence the range of generality that a standard will have. I call this the principle of contextual generality. This principle reflects the fact that the moral community, the community involved by reason of the scope of action and its effects, is a vari-

\footnotetext{
${ }^{4}$ The Ethics, IV, Prop. XVIII, Note.

${ }^{5}$ Cf. Arnold Berleant, "The Social Postulate of Theoretical Ethics", The Journal of Value Inquiry IV (1970), 1-16. See also Arnold Berleant, "The Experience and Judgment of Values", The journal of Value Inquiry I (1967), 24-37.
} 
able. But though variable, it possesses identifiable boundaries. Questions of degree do not invalidate a principle; they require knowledgeable, intelligent, and discretionary judgment to identify the limits of its application. Such limits lie characteristically at the point where the effects are markedly less significant, differences become clearly apparent and discontinuities begin to emerge. Examples of this cover the entire range of human activity, from the bell curve, body and personality types, and degrees of skill, to age groups, ethnic boundaries, and kinds of intelligence. The object is not to construct a principle that can be applied mechanically and blindly. In the history of ethical thought, moral behavior has never been considered possible without intelligent and understanding judgment.

\section{Reasonable practice}

Given these general considerations, how ought business to act in typical cases? If this approach is valid, answers can be arrived at only after determining the relevant facts and circumstances of a particular situation. As illustrations of how one might proceed, let me take two hypothetical instances for discussion, both of which concern local policy and multinational standards. The first of these, concerning the matter of wages, can be dealt with by using the principle of contextual generality. The treatment of the second, involving bribery, can be handled through the notion of structural universals.

Case 1. Wage Scales. A corporation whose home office is located in the northeast is expanding by opening two new plants, one in the south and the other in Venezuela. Among the decisions to be made are those concerning salary and wage scales. The principle of contextual generality would require equity of compensation. Accepting this, what standard should be observed? Should a uniform scale be followed at all three locations or should there be a differential scale, depending on the relative cost of living in each area, that would permit workers at the 
different locations to enjoy the same living standard? A first response might opt for the former, offering the same remuneration for the same work. The principle of equality seems self-evident. Such reasoning, however, is actually specious. Equality of pay in unequal economic circumstances is actually inequality of reward. The principle of equality would better be served by adjusting the level of compensation to the cost of living in an area, leading to different scales of compensation that would preserve the same degree of purchasing ability for the same job, irrespective of location. This would reflect the recognition that the need for sustenance and material well being is a structural universal, while allowing for monetary differences, depending on the cost of living in an area, to achieve a similar living standard.

What if the wage and salary scale or the living standard that it makes possible are lower in one location than in another? Should a differential scale be applied here to justify following the lower in order to be consistent with the local standard and so allow the company to reduce its costs? Again, if a scale preserving the same standard of living turns out to be lower at the new location than at the original one, should the corporation choose the lower as the standard to apply in all cases? To do either of these would make the principle of consistency into a principle of prudence. It would be a misuse of a flexible standard to profit from a relativistic wage scale by choosing to justify the lowest one because it is the lowest, even though the other scales be made consistent with it, just as it would be to follow the local standard when it is conveniently lower than an equitable standard at all locations would require simply because it is lower. The more difficult decision, but the moral one by the principle of contextual generality, would require a differential scale at all plants that would lead to a similarity of material reward, yet one that allows workers to meet their needs for material and psychological well being, including humane working and living conditions. The higher order principle of equal reward for equal work applies here, even though it would lead to different levels of compensation.

This, however, is still an unrealistically simple presentation. The influence of collective bargaining will be a factor in many situations, as will the financial condition of the firm itself. So, too, will the relation of a salary policy on other factors that have long term, indirect, or difficult to determine financial consequences, such as employee loyalty and efficiency. Nor can pay scales be divorced from the level of unemployment and the general economic conditions in each area, the ability to acquire a suitable 
work force, and comparable productivity ${ }^{6}$ and overhead.

In the face of all these factors, where lies the just course of action? Some basic corporate judgments must first be made on the economic value of employee loyalty and contentment. Such judgments concern more than wages, salaries, and benefits; they involve the working conditions as a whole. Factory design, employee services, personnel policies and patterns of decision making all enter into this. In establishing a policy on coordinating contracts at different locations, equity requires a comprehensive economic assessment responsive to the cost of working and living conditions and the economic strength of the corporation.

What about the condition of the labor market? Isn't that the principal factor in such decisions? Wouldn't any policy governed by moral considerations require tampering with the marketplace?

The answer to the final question is clearly, yes. For all its influence as an economic model, the marketplace has never been the standard of moral conduct; it has rather been the occasion for generating ethical deliberation. The marketplace raises the moral question; it does not answer it. And it is moral considerations that have led to many of the controls and reforms here, from minimum wage laws to non-discrimination statutes. At the source of such action is the conviction that people are a resource rather than a commodity, a non-duplicable and unexpendable resource that must not be subordinated to other values. From this point of view, the human consequences of all social action take precedence over all others. Such values accord with the recognition of the fundamental values

\footnotetext{
${ }^{6}$ In different countries productivity from performing the same task may vary as a result of plant facilities or culturally established work habits. Where this is the consequence of worker activity and not of technology or equipment, productivity may become an appropriate factor in determining an equitable wage. When, however, it results from factors not under workers' control, such as an obsolescent plant or poor working conditions, productivity is not a relevant consideration: it would be unjust to make labor pay for circumstances over which the workers have no control.
} 


\section{Multinationals and the Problem of Ethical Consistency}

embodied in the structural universal of the preservation, integrity, and well being of the group.

What happens when we expand the sphere of policy decision in this area to international dimensions? The same considerations would necessarily apply. Local workers who perform tasks similar to the American staff should receive equivalent pay to their American counterparts at the same plant and at others in this country, apart from adjustments for travel related expenses. ${ }^{7}$ Exploitation of foreign labor and resources is the curse of international industry; its correlates are found in a foreign policy toward developing nations that often encourages political and economic revolution by supporting regressive and repressive regimes and in an international standing of this country that jeopardizes our present and future relations with the Third World. The double standard of colonialism is a moral burden that international business often has assumed and carried willingly and thoughtlessly.

Case 2. Bribes. There is room for debate about the differences between a commission, a facilitating payment, a gift, and a bribe. For the purpose of this discussion, let us define the last as a substantial payment above and beyond any commission, not mentioned in the contract, and typically paid to the purchaser's agent and not to the seller's, as is the case with a kickback. In our hypothetical instance, the representative of a manufacturer of an electronic airport traffic control system is informed that in order to obtain approval of a contract with the government of a developing country, he would have to make a secret payment to the official with whom he is negotiating and who, in turn, will grant or obtain that approval. It is the country's intention to construct an international airport that will play a central role in its economic development.

\footnotetext{
7 Equivalent pay here means pay at a level sufficient to maintain the same standard of living for both local and American workers, regardless of the country. The principle of contextual generality does not sanction differential treatment. Prejudicial treatment marks American principles as hypocrisy and is taken as a sign of the generally exploitative character of foreign owned industry in a developing country. Thus an American assigned to a foreign plant should receive equivalent pay to a comparable local worker. His pay would be pegged to the local economy so that he could maintain the same standard there as he would here, with appropriate adjustments of the monetary figure up or down depending on the local economy. Local workers, too, should be treated as equals with their American counterparts in both countries and be paid identically with American workers there alongside of whom they are doing the same tasks, and equivalently with such workers in this country. How would American firms recruit qualified people for overseas employment under such conditions? Opportunities for travel and advancement are strong incentives for foreign service in their own right. It must be recognized, however, that American citizens working abroad actually inhabit two economies and two cultures: the local one and their original one to which they will return. To equalize the benefits upon their return, some compensation must be made, in the form of stock options, bonuses, or stipends, for what they may reasonably be expected to have acquired and saved had they been working in this country under the scale of compensation practiced here rather than abroad.
} 
The usual arguments for acceding to the demands of such a situation apply here. If the sales representative refuses, it is likely that the contract will go to a competitor from another country who would be less scrupulous about meeting such a request. Moreover, his job and that of the other employees of his firm depend upon securing the contract. Setting aside any legalities that may be involved, this might appear to be a situation in which everyone stands to gain, both purchaser and seller, together with their national welfare. Why, then, such widespread condemnation of the practice?

To raise this issue is, in actuality, to question the moral basis of economic relationships in general. Every economic order deals with quantities that are limited -labor, capital, resources, goods, energy, etc. It is the pattern and mechanism of distributing these quantities that distinguishes economic and social systems from one another. The effectiveness of any pattern in enabling a society to maintain and enhance its well being is the source of the relative value of these different quantities. And it is their only justification.

It is in the light of such an account that bribery associated with the marketing of high technology systems is so strongly subject to moral censure. There are political, economic, and moral arguments against bribery involving a complex of factors that may be distinguished but that cannot be separated. As a practice, bribery undermines public confidence in government, breeding cynicism, discontent, and opposition. Furthermore, bribery is not only an unnecessary cost; it is not just an unproductive and unearned reward. It is a parasitic drain on an economy's resources that contributes only by removing the obstacle that the briber, himself, has placed in the way of economic transactions. Moreover, the cost of a bribe must be inserted into the purchase price, eventually to be paid by the users of the equipment, those from whom their income derives, and ultimately all those who contribute materially to the economy of the country buying the product. Bribery imposes an additional quantity into the economic pattern, a quantity that makes no productive contribution to the economic order but rather undermines it.

Morality concerns the motives and effects of deliberate choices and acts. When, as in the case of bribery, these involve marketing practices that cross national borders, we must recognize that moral considerations cross with them. By recognizing the compelling claim of the structural 
Arnold Berleant

universal and the obstruction to economic development and social well being that bribery introduces, we can see that no society can claim moral autonomy. The need for cultural cohesion and self-direction is a primary one and economic custom and local practice must be respected. However, this does not possess the inviolability of an absolute. Our common humanity is the most fundamental of all bonds and the moral stake in human life knows no national or cultural boundaries.

Bribery in international business, then, invokes such general scope and violates such formal constraints, that the principle of contextual generality joins both parties to the transaction in the same moral sphere. But it does more than this: it implicates international business as a whole. By pitting corporation against corporation, national economy against national economy, the practice of bribery involves the world business community in a transaction that is economically unjustifiable, anthropologically unsupportable, and morally pernicious. The only defense against international bribery is international policy. An agreement among industrial exporting nations condemning and outlawing this practice will not weaken anyone's competitive advantage but rather will equalize opportunities by removing a factor that benefits none of them and injures all. ${ }^{8}$

\section{Conclusion}

The questions with which we began, then, have a range that is both personal and social, and it would be as blind to deny that the corporation occupies a moral province as it would to ignore the moral significance of individual actions. Such questions and more arise out of the practical needs of international business to conduct its affairs in a manner that furthers the interests of all the parties involved and that recognizes the moral significance and scope of its actions and policies.

International business, then, occupies a highly visible position in the moral sphere. By presenting typical moral situations on a scale and magnitude far greater than in our personal dealings, it both forces us to confront these issues and enables us to see more clearly how to respond to them. This parallels Socrates' advice in Plato's Republic to examine justice on the social scale first rather than on the individual, since, by standing larger in the social sphere, justice will appear clearer.

The international corporation stands larger, too. Its practices cannot but represent a national attitude

\footnotetext{
${ }^{8}$ In the absence of international regulation, a strong corporation is not powerless to oppose this practice. It is mistaken to assume that bribery is always engaged in or that it would be willingly entered into by all parties unless proscribed. In one case known to the author, a corporation entering into negotiations in which this may be an issue begins by stating that there are certain things it will not do, certain agents it will not deal with, and the like. This pre-empts the problem of bribes arising later.
} 
toward other countries and an economic and moral policy that embodies it. Moreover, in a broader sense the multinational corporation transcends national boundaries entirely, frequently exceeding nations in wealth, size and complexity of organization, and power. Under such conditions the corporation is no longer under the influence of national goals and may not be bound by national loyalty . Rather than condoning expediency and narrow self-interest, this condition requires the supranational corporation to assume the larger concerns of the state and to act with concern far and responsibility toward all those who lie under its influence. Moral leadership is not empty rhetoric; it affects the conditions of individual and social life. In an industrialized world, the policies and standards of major companies have a pervasive influence and a compelling effect. While this essay is not intended to provide a practical guide for decision-making in particular cases, perhaps it can serve to indicate ways in which moral action may properly proceed. In moral matters more than others, one cannot acquiesce in the comfortable injustices of the status quo. It is necessary at times to nudge history, as a colleague has remarked, and press the pace of change. In the long run, far-sighted policies are goad business. Enlightened guidance in developing such policies requires breadth of scope and subtlety of judgment. Perhaps some of the issues and ideas that have been discussed here can help in promoting such ends.

Notes

* An earlier version of this paper was presented at the Fifteenth Conference on Value Inquiry at the SUNY College at Genesco on 17 April 1981 and published in the Proceedings of that conference.

In some instances negotiations proceed no further, but in a surprising number of cases they continue to a satisfactory conclusion. 
193Multinationals and the Problem of Ethical Consistency 